\title{
Effects of graphene oxide on the performance, microbial community dynamics and antibiotic resistance genes reduction during anaerobic digestion of swine manure
}

\author{
Junya Zhang ${ }^{\mathrm{a}, \mathrm{b}, \mathrm{c}}$, Ziyue Wang ${ }^{\mathrm{d}}$, Yawei Wang ${ }^{\mathrm{a}, \mathrm{b}, \mathrm{c}}$, Hui Zhong ${ }^{\mathrm{a}, \mathrm{b}, \mathrm{c}}$, Qianwen Sui ${ }^{\mathrm{a}, \mathrm{b}, \mathrm{c}}$, \\ Changping Zhang ${ }^{\mathrm{d}}$, Yuansong Wei ${ }^{\mathrm{a}, \mathrm{b}, \mathrm{c}, *}$ \\ a State Key Joint Laboratory of Environmental Simulation and Pollution Control, Research Center for Eco-Environmental Sciences, Chinese Academy of Sciences, Beijing \\ 100085, China \\ b Department of Water Pollution Control Technology, Research Center for Eco-Environmental Sciences, Chinese Academy of Sciences, Beijing 100085, China \\ c University of Chinese Academy of Sciences, 100049 Beijing, China \\ d School of Energy and Environmental Engineering, Hebei University of Technology, Tianjin 300401, China
}

\section{A R T I C L E I N F O}

\section{Keywords:}

Antibiotic resistance genes

Graphene oxide

Anaerobic digestion

Swine manure

Methane production

\begin{abstract}
A B S T R A C T
The role of graphene oxide (GO) on anaerobic digestion (AD) of swine manure concerning the performance, microbial community and antibiotic resistance genes (ARGs) reduction was investigated. Results showed that methane production was reduced by $13.1 \%, 10.6 \%, 2.7 \%$ and $17.1 \%$ at GO concentration of $5 \mathrm{mg} / \mathrm{L}, 50 \mathrm{mg} / \mathrm{L}$, $100 \mathrm{mg} / \mathrm{L}$ and $500 \mathrm{mg} / \mathrm{L}$, respectively, but propionate degradation was enhanced along with GO addition. Both bacterial and archaeal community changed little after GO addition. AD could well reduce ARGs abundance, but it was deteriorated at the GO concentration of $50 \mathrm{mg} / \mathrm{L}$ and $100 \mathrm{mg} / \mathrm{L}$ and enhanced at $500 \mathrm{mg} / \mathrm{L}$, while no obvious changes at $5 \mathrm{mg} / \mathrm{L}$. Network and SEM analysis indicated that changes of each ARG was closely associated with variation of microbial community composition, environmental variables contributed most to the dynamics of ARGs indirectly, GO influenced the ARGs dynamics negatively and (heavy metal resistance genes (MRGs)) influenced the most directly.
\end{abstract}

\section{Introduction}

Antibiotic resistance threatened the public health more and more seriously, and ARGs was generally considered as an emerging pollutant (Dang et al., 2017). The use of antibiotics in the farming made a huge contribution to the improvement of the human living standard, because antibiotics could not only preserve the disease but also promote the growth and the feed efficiency in the livestock, which warranted the increasing demand for animal protein (Boeckel et al., 2015). China is the biggest antibiotics consumer and producer, and it was estimated that the total antibiotics consumption was 162,000 tons and 84,240 tons (ca. 52\%) were used for the animals (Zhang et al., 2015). Thus, manure became an important reservoir of antibiotic resistance genes (ARGs), especially in Chinese swine farms (Larson, 2015).

China raised and consumed half the planet's pigs, which produced an estimated 618 billion kilograms of manure every year (Larson, 2015). Considering the huge amounts of swine manure, anaerobic digestion (AD) was widely adopted due to its effectiveness on the pathogens removal, volume reduction and resource utilization, especially the biogas production, and luckily, it was demonstrated that AD could also realize some ARGs reduction in swine manure (Youngquist et al., 2016). But the digestate still contributed a lot to the spread and proliferation of ARGs in the environment (Sui et al., 2016) and there was much space for the improvement of AD efficiency (Astals et al., 2012), which indicated that some work could be done to simultaneously enhance the AD efficiency and ARGs removal.

Graphene oxide (GO) has attracted significant attention due to its remarkable structural, chemical, mechanical, and electronic properties and has shown great application potential in many fields (Zou et al., 2016). GO was reported to enhance the growth of human gut bacteria while inhibit the proliferation of pathogens (Chen et al., 2014), and the activity of anammox bacteria for the nitrogen removal could be enhanced by GO addition (Wang et al., 2013a,b; Wang et al., 2014). Also, it was demonstrated that the enhancement of microbes proliferation under methanogenic conditions was elucidated through the electron shuttle effects of GO, and graphene could boost the biomethane yield and production rate due to the enhancement of direct interspecies electron transfer in AD (Colunga et al., 2015; Lin et al., 2017).

\footnotetext{
* Corresponding author at: Department of Water Pollution Control Technology, Research Center for Eco-Environmental Sciences, Chinese Academy of Sciences, Beijing 100085, China.

E-mail address: yswei@rcees.ac.cn (Y. Wei).
} 
However, GO could also cause acute toxicity on activated sludge, and the toxic effects were dose dependent (Ahmed and Rodrigues, 2013). While the effects of GO addition on the performance and its microbial mechanisms of swine manure AD have never been clarified.

Moreover, It has been demonstrated that GO has the potential ability to control the antibiotics uptake and ARGs transfer because of the high surface area and the specific $\mathrm{sp}^{2} / \mathrm{sp}^{3}$ structure (Zou et al., 2016), and GO nanosheets exhibited excellent removal efficiency on ARGs in aquatic environments due to the physical absorption and the GO-ARG noncovalent combination (Yu et al., 2016). But the ARGs types and abundances in mouse gut increased after the GO exposure (Xie et al., 2016), and Guo and Zhang (2017) indicated that GO concentration above $10 \mathrm{mg} / \mathrm{L}$ can damage resistant plasmids, but GO concentrations lower than $1 \mathrm{mg} / \mathrm{L}$ led to almost no damage. Further research is needed to evaluate the overall effects of GO on the ARGs control in various environments. Then, considering the increasing ARGs pollution in swine manure, whether the GO addition during swine manure $\mathrm{AD}$ could favor the enhancement of ARGs removal deserved to be elucidated.

In this study, batch experiments of swine manure $\mathrm{AD}$ at the $\mathrm{GO}$ addition of $0 \mathrm{mg} / \mathrm{L}, 5 \mathrm{mg} / \mathrm{L}, 50 \mathrm{mg} / \mathrm{L}, 100 \mathrm{mg} / \mathrm{L}$ and $500 \mathrm{mg} / \mathrm{L}$ were established to find out the effects of GO on the performance and ARGs reduction. Microbial community dynamics were studied to explore the microbial mechanisms. Besides, swine manure not only contained high amounts of antibiotics but also heavy metals and human potential pathogens (Pal et al., 2015; Zhang et al., 2016). The co-selection from heavy metals to ARGs has been widely demonstrated (Pal et al., 2015), and the co-occurrence of virulence factors in human potential pathogens with ARGs generally existed (Zhang et al., 2016). Thus, heavy metal resistance genes (MRGs) to reflect the heavy metal selective pressure and virulence factors (VFs) to reflect the human pathogens were investigated to link the factors influencing the ARGs profiles.

\section{Materials and methods}

\subsection{Materials}

Swine manure was collected from an intensive pig farming facility in Beijing, China, and the farm run an up-flow solid reactor heated by solar and controlled at $37^{\circ} \mathrm{C}$. The total solids (TS) and volatile solids (VS) of the swine manure were $28.3 \%$ and $80.4 \%$, respectively. Seed sludge was collected from the same facility, and the TS and VS of the seed sludge were $4.9 \%$ and $55.8 \%$, respectively. GO nanosheets (XF0021) were obtained from the Nanjing XFNANO Materials Tech Co., Ltd., China. The synthesis method was Hummers, diameter was $500 \mathrm{~nm}$ $5 \mu \mathrm{m}$, Thickness was $0.8-1.2 \mathrm{~nm}$, the single layer ratio was ca. $99 \%$ and the purity was above $99 \mathrm{wt} \%$. The GO nanosheets were suspended in deionized water to prepare the stock solutions at the concentration of $2 \mathrm{mg} / \mathrm{mL}$ by sonication dispersion method for ca. $2 \mathrm{~h}$.

\subsection{Batch experiments set-up}

Batch experiments were set up by using the Automatic Methane Potential Test System II (Bioprocess Control, Sweden) in which digesters were a series of serum bottles (working volume: $0.4 \mathrm{~L}$ ) equipped with a sampling tap and plastic caps including agitators and rubber stoppers. The mixing was semi-continuous at the rate of $150 \mathrm{rpm}$ in the cycle of 1 min mixing and $1 \mathrm{~min}$ resting. Swine manure and seed sludge used for the batch experiments were mixed thoroughly at a ratio of 3:1 (TS), and then, $0.4 \mathrm{~L}$ of the mixture were transferred to each bottle. The final TS was adjusted to ca. 8\%. Appropriate volumes of GO stock solution were added to the bottles to attain the final concentrations of $0 \mathrm{mg} / \mathrm{L}$ (Control), $5 \mathrm{mg} / \mathrm{L}$ (GO-5), $50 \mathrm{mg} / \mathrm{L}$ (GO-50), $100 \mathrm{mg} / \mathrm{L}$ (GO$100)$ and $500 \mathrm{mg} / \mathrm{L}(\mathrm{GO}-500)$. Each treatment was set in triplicate. After sealing, the headspaces were flushed with nitrogen gas for 3-5 min to remove traces of oxygen. Then the bottles were incubated in a water bath to control temperature at ca. $37^{\circ} \mathrm{C}$. The methane production were automatically measured excluding $\mathrm{CO}_{2}$ which was removed by a gas-washing bottle containing $3 \mathrm{M} \mathrm{NaOH}$ solution. The batch experiments lasted for 22 days, and sampling was conducted on days $0,5,13$ and 22 for further analysis.

\subsection{Chemical analysis}

TS was determined by drying a $10-\mathrm{ml}$ sub-sample for $24 \mathrm{~h}$ at $105^{\circ} \mathrm{C}$, and dried solids were incinerated for $1 \mathrm{~h}$ at $600{ }^{\circ} \mathrm{C}$ to constant weight for VS measurement. Samples were centrifuged at $4000 \mathrm{rpm}$ for $10 \mathrm{~min}$ and filtered through $0.45-\mu \mathrm{m}$ cellulose membrane. The filtrate was analyzed for $\mathrm{pH}, \mathrm{NH}_{4}{ }^{+}-\mathrm{N}$, Total and soluble chemical oxygen demand (TCOD and SCOD), proteins, polysaccharides and VFAs as previously described (Zhang et al., 2016).

\subsection{DNA extraction}

$0.5 \mathrm{~mL}$ of each sludge sample was used for DNA extraction using FastDNA Spin Kit for Soil (MP Biomedicals, USA) according to manufacturer's instructions, and quality and concentration of the extracted DNA were determined through $1 \%$ agarose gel electrophoresis and NanoDrop ND-1000 (NanoDrop, USA), respectively. The three resulting extracts from the same treatment on each sampling day were composited to get a representative DNA sample for further analysis.

\subsection{Microbial community analysis}

Both bacterial and archaeal community changes were followed through high-throughput sequencing method, and the primers 515F/ 806R were selected mainly for bacterial community analysis, while archaeal community was analyzed using the nested PCR by the primers Arch340F/Arch1000R and Arch349F/Arch806R as previously described (Zhang et al., 2016). Amplicons were then sent out to Sangon Co., Ltd., in Shanghai for small-fragment library construction and pairend sequencing using the Illumina MiSeq sequencing system (Illumina, USA).

Pair-end reads were firstly merged using PEAR $(-x, 0.1)$, and then sequencing reads were assigned to each sample according to the unique barcode. PRINSEQ was used for the quality control of these merged reads. PCR chimeras were filtered out through UCHIME to get the clean sequences. The clean sequences were normalized to the same sequencing depth (ca. 24 000) for further analysis. The clean sequences were submitted to the NCBI Sequence Read Archive (SRA) under the project number of PRJNA388021. The taxonomic classification of the sequences was carried out using the Ribosomal Database Project (RDP) Classifier, and the classifier data was denoised through the package ade4 in R. The OTUs with an abundance below $0.01 \%$ were removed. The alpha diversity index including Shannon, ACE, Chao1 and Simpson were calculated through the Mothur software package (https://www. mothur.org/).

\section{6. $q P C R$}

Nine frequently detected and widely existed ARGs including sulI, sulII, ermB, ermF, bla $a_{\mathrm{CTX}-\mathrm{M}}, b l a_{\mathrm{TEM}}, t e t M, \operatorname{tet} G$ and tet $X$ were selected to represent the changes of ARGs in swine manure (Luby et al., 2016). Also, the recently emerged plasmid-mediated polymixin resistance gene, $m c r-1$, with high dissemination risk was chosen, while it has never been quantified in swine manure (Liu et al., 2015). The changes of intI1 representing the mobile genetic elements (MGEs) was followed to reflect the potential of HGT and multi-resistance (Engelstädter et al., 2016). The functional gene $m c r A$ involved the methane production was quantified to reflect the effects of GO addition on the methanogenesis (Ziganshin et al., 2016).

MRGs including merA, $p c o A$, $\operatorname{ars} C$ and $c z c A$ were chosen to represent 
the selection pressure from $\mathrm{Hg}, \mathrm{Cu}, \mathrm{As}, \mathrm{Co}, \mathrm{Zn}$ and $\mathrm{Cd}$, respectively, which belonged to the typical heavy metals existed in swine manure (Wang et al., 2013a,b). VFs in typical potential pathogens of swine manure including Escherichia coli (eaeA) and Enterococcus faecium (asa1) were chosen to present the changes of real pathogens with pathogenicity (Paton and Paton, 1998; Vankerckhoven et al., 2004). The qPCR process was described as previously described (Zhang et al., 2017), and the primers, annealing temperature and the corresponding amplification efficiencies in this study were summarized in Tables S1 and S2.

\subsection{Data analysis}

Free ammonia concentration was calculated using the formula (Hansen et al., 1998): Free ammonia $=\left(\right.$ Total $\mathrm{NH}_{4}{ }^{+}$$\mathrm{N}) \times\left(1+10^{-\mathrm{pH}} / 10^{-(0.09018}+2729.92 / \mathrm{T}\right)^{-1}$, and $\mathrm{T}$ indicated the temperature (Kelvin). The heat map of the top 10 genus in each sample based on $\log 2$ transformed of the abundance was built through the HemI (http://hemi.biocuckoo.org/). Principal component analysis (PCA) was performed using Canoco 5.0 (http://www.canoco5.com/). Network based on spearman analysis and structural equation model (SEM) based on the correlation matrix were conducted through Gephi (https://gephi.org/) and AMOS (SPSS Inc., Chicago, IL, USA), respectively. The abundance indicated the specific gene copies divided by the corresponding $16 \mathrm{~s}$ rRNA gene copies.

\section{Results and discussion}

\subsection{Effects of $G O$ addition on the performance}

\subsubsection{Methane production}

The methane production reached $297.66 \pm 4.02 \mathrm{~mL} \quad \mathrm{CH}_{4}$ $\mathrm{g}^{-1} \mathrm{VS}_{\text {added }}$ for the Control, which was comparable to other studies concerning the swine manure AD (Abdelsalam et al., 2017), while GO addition reduced the accumulative methane production. The methane reduction rate was $13.06 \pm 6.96 \%, 10.60 \pm 5.98 \%, 2.68 \pm 1.21 \%$ and $17.07 \pm 1.51 \%$ for the GO-5, GO-50, GO-100 and GO-500, respectively, compared to the Control (Fig. 1A). The methane reduction was not dose-dependent, and the maximum reduction was at $5 \mathrm{mg} / \mathrm{L}$ and $500 \mathrm{mg} / \mathrm{L}$, while the least methane reduction at the GO addition of $100 \mathrm{mg} / \mathrm{L}$.

There existed two peaks (D2 and D11 12) on the daily methane production shown in Fig. 1B. The first peak period lasted for ca. 3 days, while the second peak, ca. 10 days, and the reduction of methane production due to GO addition mainly happened at the second peak. It was deemed that the first peak was attributed to the fast degradation of easily degradable organics, while the second peak derived from the poorly biodegradable organics.

\subsubsection{Chemical parameters}

Interestingly, although accumulative methane production was reduced after GO addition, the VS reduction was increased by $5.71-16.77 \%$, and the TS reduction also increased in all the treatments (maximum, 7.79\%) except GO-5, which was in accordance with the changes of TCOD (Table 1). These indicated that although methane production was reduced after GO addition, the volume reduction was enhanced. The experimental set-up excluded the $\mathrm{CO}_{2}$ production, and it was speculated that $\mathrm{GO}$ addition should have increased the $\mathrm{CO}_{2}$ production which was absorbed by the gas-washing bottles, while this needed further detail investigation.

The GO addition had little influence on the changes of $\mathrm{pH}$ and $\mathrm{NH}_{4}{ }^{+}-\mathrm{N}$ concentration, and they increased to the maximum at D13 and D5, respectively, while free ammonia reached its maximum at D13. The increase of $\mathrm{NH}_{4}{ }^{+}-\mathrm{N}$ was due to the degradation of organics like proteins, while the delay of the maximum of $\mathrm{pH}$ could be attributed to the balance of VFAs accumulation and $\mathrm{NH}_{4}{ }^{+}-\mathrm{N}$ concentration.

\subsubsection{VFAs}

During the first peak, the methane production was mainly from the acetate and butyrate fermentation, while it was iso-valerate and propionate fermentation for the methane production at the second peak (Fig. 2). There was no much difference at the first peak between treatments, while the propionate fermentation was increasingly

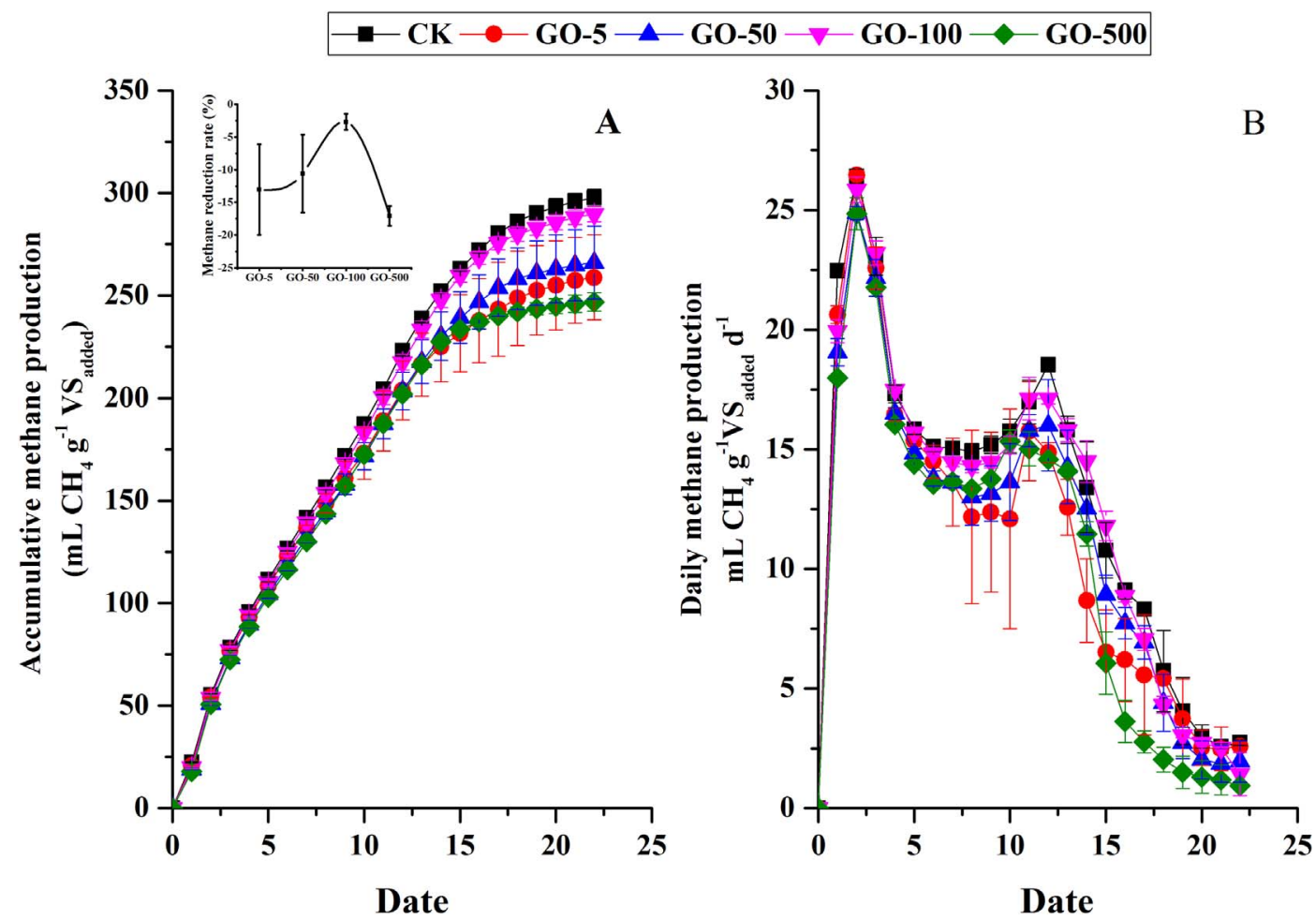

Fig. 1. The profiles of accumulative (A) and daily (B) methane production during swine manure AD. 
Table 1

The characteristics of materials and samples during anaerobic digestion in this study.

\begin{tabular}{|c|c|c|c|c|c|c|c|c|c|c|}
\hline Samples & & $\mathrm{pH}$ & TCOD $(\mathrm{g} / \mathrm{L})$ & $\operatorname{SCOD}(\mathrm{g} / \mathrm{L})$ & $\mathrm{NH}_{4}{ }^{+}-\mathrm{N}(\mathrm{g} / \mathrm{L})$ & Free ammonia $(\mathrm{g} / \mathrm{L})$ & Proteins $(\mathrm{g} / \mathrm{L})$ & Polysaccharides $(\mathrm{g} / \mathrm{L})$ & TS (\%) & VS (\%) \\
\hline Manure & & $7.20 \pm 0.01$ & - & - & - & - & - & - & $28.28 \pm 0.04$ & $80.41 \pm 0.15$ \\
\hline Seed & & $7.52 \pm 0.04$ & $35.52 \pm 2.47$ & $5.44 \pm 0.45$ & $3.32 \pm 0.08$ & 0.14 & - & - & $4.90 \pm 0.01$ & $55.78 \pm 0.17$ \\
\hline D0 & & $7.48 \pm 0.09$ & $75.57 \pm 2.77$ & $13.73 \pm 0.56$ & $2.01 \pm 0.06$ & 0.07 & 5.02 & 0.68 & $7.66 \pm 0.03$ & $73.99 \pm 0.04$ \\
\hline \multirow[t]{3}{*}{ Control } & D5 & $7.61 \pm 0.04$ & $61.31 \pm 5.40$ & $13.60 \pm 0.23$ & $3.22 \pm 0.09$ & 0.16 & 5.35 & 0.58 & - & - \\
\hline & D13 & $7.69 \pm 0.02$ & $48.32 \pm 2.01$ & $11.99 \pm 0.59$ & $2.97 \pm 0.07$ & 0.18 & 5.12 & 0.50 & - & - \\
\hline & D22 & $7.52 \pm 0.02$ & $44.69 \pm 3.61$ & $7.19 \pm 0.08$ & $3.00 \pm 0.09$ & 0.12 & 4.46 & 0.41 & $4.88 \pm 0.14$ & $62.44 \pm 1.95$ \\
\hline \multirow[t]{3}{*}{ GO-5 } & D5 & $7.59 \pm 0.01$ & $66.03 \pm 1.53$ & $13.08 \pm 0.21$ & $3.06 \pm 0.02$ & 0.15 & 5.60 & 0.56 & - & - \\
\hline & D13 & $7.71 \pm 0.03$ & $49.59 \pm 1.10$ & $11.75 \pm 0.76$ & $2.84 \pm 0.18$ & 0.18 & 4.85 & 0.59 & - & - \\
\hline & D22 & $7.57 \pm 0.04$ & $46.72 \pm 0.99$ & $7.01 \pm 0.38$ & $3.13 \pm 0.06$ & 0.14 & 4.59 & 0.46 & $5.22 \pm 0.05$ & $59.50 \pm 0.06$ \\
\hline \multirow[t]{3}{*}{ GO-50 } & D5 & $7.61 \pm 0.03$ & $59.52 \pm 5.18$ & $12.69 \pm 0.36$ & $3.05 \pm 0.10$ & 0.15 & 5.29 & 0.68 & - & - \\
\hline & D13 & $7.73 \pm 0.03$ & $47.52 \pm 1.31$ & $11.92 \pm 0.17$ & $3.00 \pm 0.09$ & 0.19 & 5.35 & 0.51 & - & - \\
\hline & D22 & $7.55 \pm 0.05$ & $44.50 \pm 3.69$ & $7.83 \pm 1.05$ & $3.13 \pm 0.03$ & 0.14 & 5.21 & 0.38 & $5.01 \pm 0.12$ & $61.74 \pm 1.66$ \\
\hline \multirow[t]{3}{*}{ GO-100 } & D5 & $7.60 \pm 0.01$ & $62.40 \pm 2.79$ & $12.73 \pm 0.25$ & $3.04 \pm 0.06$ & 0.15 & 5.71 & 0.67 & - & - \\
\hline & D13 & $7.76 \pm 0.09$ & $45.61 \pm 1.20$ & $10.38 \pm 1.00$ & $2.70 \pm 0.02$ & 0.19 & 5.51 & 0.41 & - & - \\
\hline & D22 & $7.51 \pm 0.01$ & $43.37 \pm 3.48$ & $7.21 \pm 0.14$ & $3.10 \pm 0.12$ & 0.12 & 4.29 & 0.37 & $5.05 \pm 0.16$ & $62.22 \pm 2.19$ \\
\hline \multirow[t]{3}{*}{ GO-500 } & D5 & $7.54 \pm 0.01$ & $58.19 \pm 5.66$ & $12.67 \pm 0.22$ & $3.02 \pm 0.09$ & 0.13 & 6.32 & 0.66 & - & - \\
\hline & D13 & $7.81 \pm 0.02$ & $47.48 \pm 3.92$ & $8.75 \pm 0.45$ & $2.75 \pm 0.04$ & 0.21 & 5.05 & 0.40 & - & - \\
\hline & D22 & $7.59 \pm 0.06$ & $43.25 \pm 2.18$ & $6.83 \pm 0.10$ & $2.96 \pm 0.05$ & 0.14 & 5.03 & 0.32 & $5.28 \pm 0.03$ & $60.97 \pm 1.25$ \\
\hline
\end{tabular}

enhanced along with the GO addition concentrations at the second peak. The propionate accumulation removal rate was $2.71 \%, 3.40 \%$, $5.34 \%$ and $10.51 \%$ for the GO-5, GO-50, GO-100 and GO-500, respectively, while it was $3.63 \%$ for the Control. Propionate is an important intermediate of the degradation of organic matter during $\mathrm{AD}$, and due to thermodynamic constraints, the oxidation of propionate requires syntrophic cooperation of propionate-fermenting proton-reducing bacteria and $\mathrm{H}_{2}$-consuming methanogens (Narihiro et al., 2012). Graphene had been demonstrated to enhance the methane production during ethanol (also a key intermediate produce for the methane production) $\mathrm{AD}$ due to the enhancement of the direct interspecies electron transfer (DIET) (Lin et al., 2017). It seemed that the DIET of the propionate fermentation was also enhanced during swine manure $\mathrm{AD}$, but what was different was that the oxygenic groups in the GO might also delivered the oxygen to the methanogens, which led to higher $\mathrm{CO}_{2}$ production during swine manure $\mathrm{AD}$. This could well explain the enhancement of VS, TS and TCOD removal but reduction of methane production after GO addition, while this needed further investigation to elucidate the hypothesis.

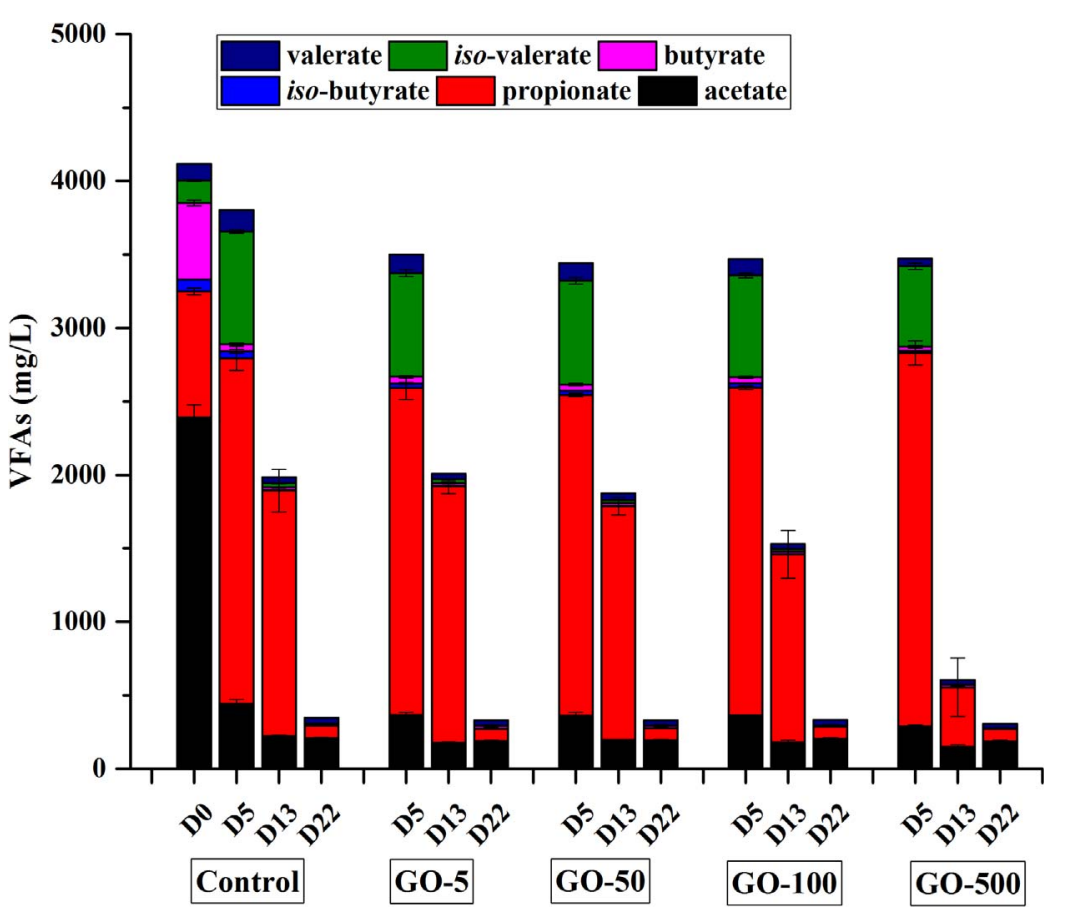

\subsection{Effects of GO addition on microbial community dynamics}

\subsubsection{Changes of bacterial community}

The microbial diversity decreased after $\mathrm{AD}$, and there existed little influence on the changes of microbial diversity after GO addition even at $500 \mathrm{mg} / \mathrm{L}$ (Table S3 and Fig. S1). Firmicutes and Bacteroidetes dominated throughout the $\mathrm{AD}$, and the abundance of Firmicutes reached to 91\% in the manure, while Firmicutes and Bacteroidetes accounted for $57 \%$ and $32 \%$ in the seed sludge, respectively. All the treatments showed the same trends that Firmicutes increased, while Bacteroidetes decreased along with AD between D5 and D22 (Fig. S2). There was no much difference at the phylum level between treatments.

$\mathrm{AD}$ was carried out by different groups of microorganisms involved in hydrolysis, acidogenesis, acetogenesis and methanogenesis, and they were not separated steps but unified processes. In order to find out which step GO addition impacted, the microbial community was further analyzed at genus level. The genus of unclassified_Ruminococcaceae (10-25\%), Clostridium sensu stricto (10-19\%), Clostridium III (2-10\%) and unclassified_Bacteroidales $(6.25-23.28 \%)$ were famous for the
Fig. 2. Changes of VFAs accumulation during the BMP tests of swine manure with different concentrations of GO addition. 

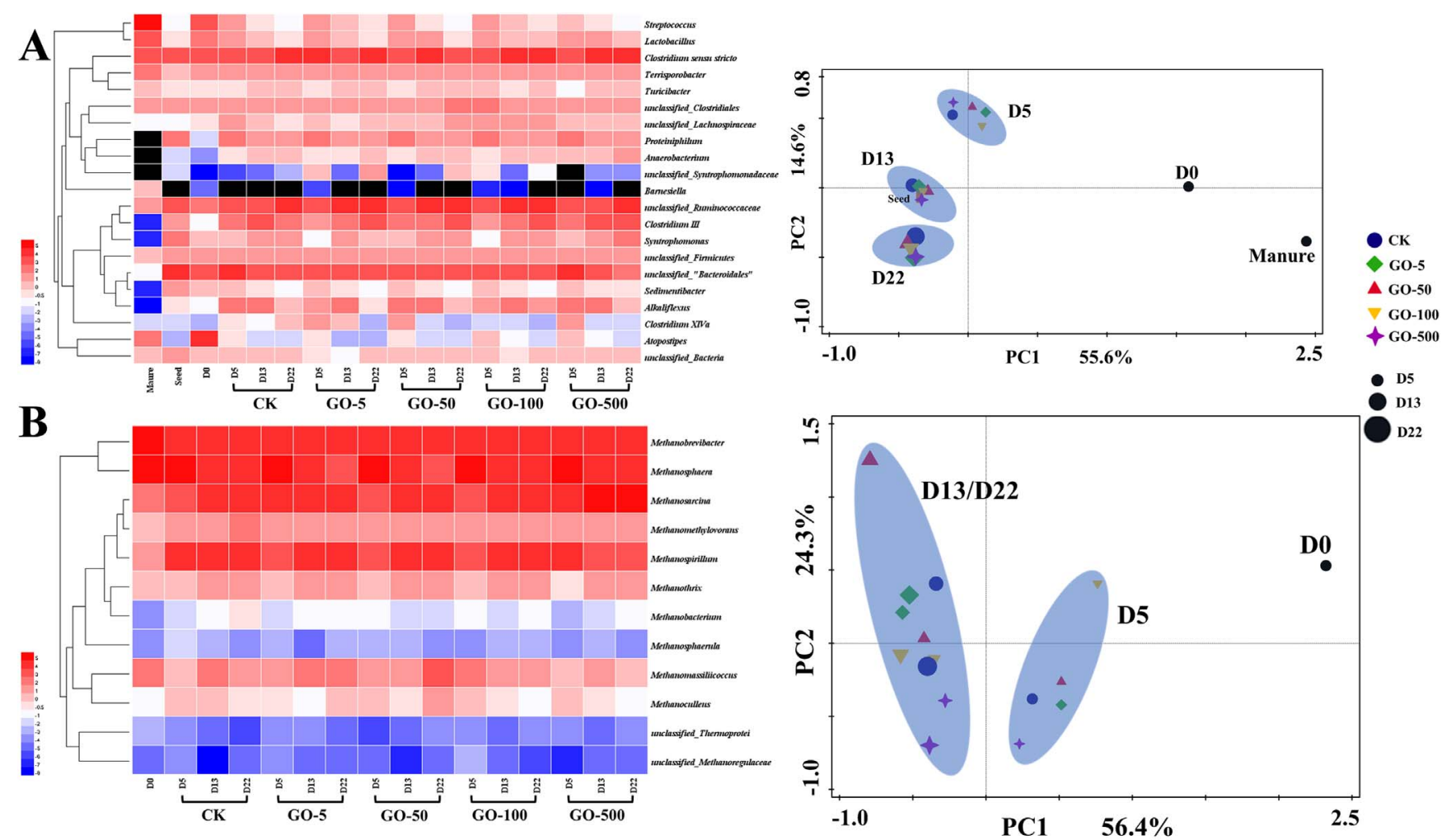

Fig. 3. The heatmap and PCA analysis of changes of bacterial (A) and archaeal community (B) after GO addition.

hydrolysis and acidogenesis. They were dominant throughout the AD, which indicated that the hydrolysis and acidogenesis happened all the time. This was associated with the co-occurrence of readily, poorly and non-biodegradable organics in swine manure. The genus Alkaliflexus existed in high abundance at D5 and D13, and it utilized several carbohydrates, in particular those that may result from the hydrolysis of cellulose, hemicelluloses and other natural polysaccharides (Zhilina et al., 2004). The main fermentation products were propionate and acetate, which contributed to the propionate accumulation.

Acetate, $\mathrm{H}_{2}$ and $\mathrm{CO}_{2}$ etc., could be directly used by methanogens for the biogas production, while VFAs like propionate, butyrate needed further degradation by the syntrophic bacterium. In this study, the dominant syntrophic bacteria was Syntrophomonas which degraded butyrate in co-culture with methanogens or hydrogen-utilizing sulfatereducing bacteria, and the genus reached the maximum at D13 (2-4\%). This was in accordance with the rapid removal of VFAs accumulation (Fig. 2), and interestingly, the abundance of Syntrophomonas in the GO addition was generally higher than the Control. This well explained the enhancement of VFAs accumulation removal through the GO addition. As for the central intermediate, propionate, which can be converted to methane and acetate only by the concerted action of syntrophic bacteria and methanogens, because of its highest energetics difficulties (Narihiro et al., 2012), its syntrophic bacterium like Smithella, Syntrophobacter and Pelotomaculum etc., were not detected or at much lower abundance $(<0.01 \%)$. The genus Smithella and Syntrophobacter belonged to the phylum of Proteobacteria whose abundance was below 1\%. Pelotomaculum belonged to Firmicutes, but its abundance was below $0.01 \%$. These indicated that there existed some new species accounting for the syntrophic propionate-degrading that has not been known. Interestingly, there existed considerable abundance of Proteiniphilum (2 5\%) which could not consume propionate of synthesize methane itself but accelerate the propionate-degradation rate (Chen and Dong, 2005). Besides, Streptococcus (32\%), Lactobacillus (15\%), and Atopostipes $(6 \%)$ which dominated in swine manure could not well adapt to the $\mathrm{AD}$ and were reduced to below $1 \%$ after $\mathrm{AD}$. The genus Streptococcus were famous human potential pathogens, which highlighted the effects of $\mathrm{AD}$ on pathogens removal.

\subsubsection{Changes of archaeal community}

Although the primers $515 \mathrm{~F} / 806 \mathrm{R}$ also targeted the archaeal community, the abundance of Euryarchaeota was much lower (0.6-1.9\%) than the bacteria, thus, archaeal community were further investigated using the primers specially targeting the archaeal community. The qPCR results of mcrA also demonstrated the lower abundance of archaeal community in the seed (1.2\%), and there also existed considerable abundance of archaeal community in swine manure (ca. 0.4\%) (Fig. S4).

The dominant archaea were Methanosarcina, Methanobrevibacter, Methanosphaera and Methanospirillum, and Methanosarcina increased from $6 \%$ to $20-36 \%$ after $\mathrm{AD}$, while it was not detected in swine manure and at the abundance of $0.3 \%$ in the seed through the primer $515 \mathrm{~F} / 806 \mathrm{R}$, which indicated its origin from the seed. The dominance of Firmicutes and Methanosarcina were also observed previously (Ziganshin, 2014). Methanospirillum was similar to the pattern of $M e$ thanosarcina and increased from $2 \%$ to $14-31 \%$. However, the abundance of Methanosphaera and Methanobrevibacter in swine manure was $0.6 \%$ and $0.8 \%$, respectively, while it was $0.09 \%$ and $0.06 \%$ in the seed, respectively through the primers 515F/806R, which indicated their origin from the swine manure. The abundance of Methanobrevibacter and Methanosphaera decreased from $46 \%$ and $36 \%$ to $18 \sim 24 \%$ and $12 \sim 18 \%$, respectively. The genus Methanosphaera could only utilize the methanol for the methane production, and Methanobrevibacter and Methanospirillum could use $\mathrm{H}_{2}, \mathrm{CO}_{2}$ and formate excluding acetate, while Methanosarcina could utilize $\mathrm{H}_{2}, \mathrm{CO}_{2}$ and acetate excluding formate (Garcia, 1990). Thus, it was concluded that the acetate was mainly consumed by Methanosarcina, while the $\mathrm{H}_{2}$ and $\mathrm{CO}_{2}$ were consumed by Methanobrevibacter and Methanospirillum.

VFAs like propionate and butyrate could only be consumed by the co-work of syntrophic bacterium and hydrogen utilizing methanogens, which indicated that the existence of Methanobrevibacter and 
Methanospirillum was the key methanogens for the removal of VFAs accumulation, and the symbiosis of Syntrophobacter and Syntrophomonas with Methanospirillum was widely observed for the propionate or butyrate degradation for methane production (Chen et al., 2005; Zhang et al., 2004). Besides, in the presence of high amounts of ammonia (above $2.8-3 \mathrm{~g} / \mathrm{L}$, Table 1 ), acetate sink for the methane production via the activity of syntrophic acetate oxidizing bacteria coupled with hydrogen utilizing methanogen like Methanobrevibacter and Methanospirillum should not be overlooked (Fotidis et al., 2014; Schnürer and Nordberg, 2008).

\subsubsection{Effects of $G O$ addition}

There existed no significant difference between treatments as revealed by the PCA analysis considering the bacterial and archaeal community dynamics (Fig. 3), and this indicated that the reduction of methane production and enhancement of VS reduction may be due to that the GO impacted the microbial activity more than the microbial community composition. In order to elucidate the hypothesis, the key functional gene $m c r A$ was quantified, the abundance of $m c r A$ increased along with swine manure $\mathrm{AD}$ in all treatments, and it was increased significantly along with GO addition compared to the Control (Fig. S3). The mcrA gene abundance had been demonstrated to be able to well correlate with the activity measurements of methanogenic $\mathrm{H}_{2} / \mathrm{CO}_{2}$ enriched anaerobic biomass (Venkiteshwaran et al., 2017), thus, this confirmed that the GO addition enhanced the key functional enzymes not changing the microbial community composition.

There was no much difference of $m c r A$ gene abundance at D5 between treatments, but the $m c r A$ gene abundance changed significantly at D13, which could well explain the main methane production due to GO addition happened at the second peak. Interestingly, the methane production correlated significantly negatively with $\mathrm{mcrA}$ gene abundance, while GO-100 was a special point. As for the special point of GO100 , this could be explained by the three action mode between GO and microbes including cutting, wrapping and trapping (Palmieri et al., 2017). Cutting and trapping did not kill the methanogens, but enhanced the DIET between syntrophic bacterium and methanogens, while wrapping could cause the membrane and oxidative stress which further killed or inhibited the methanogens, and it was speculated that GO showed the cutting effects at the concentration of $5 \mathrm{mg} / \mathrm{L}$ and $50 \mathrm{mg} / \mathrm{L}$, while it was wrapping and trapping effects at $100 \mathrm{mg} / \mathrm{L}$ and $500 \mathrm{mg} / \mathrm{L}$, respectively. At the end of the swine manure $\mathrm{AD}, \mathrm{mcrA}$ gene abundance still increased, and this could be due to that methanogens could stand the poor nutrition environments compared to other microbes (Garcia et al., 2000).

\subsection{Effects of GO addition on ARGs, MRGs, VFs and intI1 reduction}

\subsubsection{Changes of total ARGs}

There existed high abundance of ARGs, MRGs, VFs and intI1 in both swine manure and seed (Fig. S5), and the total ARGs abundance in the seed $\left(3.01 \times 10^{-1}\right)$ was higher than the swine manure $\left(1.91 \times 10^{-1}\right)$. This was because the seed sludge were collected from the AD system treating the swine manure long-termly, but the MRGs and intI1 in the seed $\left(8.12 \times 10^{-4}\right.$ and $\left.1.80 \times 10^{-3}\right)$ were much lower than swine manure $\left(1.89 \times 10^{-4}\right.$ and $\left.1.04 \times 10^{-3}\right)$.

As shown in Fig. 4, AD could effectively realize the ARGs, MRGs, VFs and intI1 gene abundance reduction. Total ARGs abundance changed little at D5 in all treatments, that is the hydrolysis and acidogenesis, but it decreased significantly as $\mathrm{AD}$ progressed to the acetogenesis and methanogenesis, which indicated that ARGs reduction was realized mainly through the acetogenesis and methanogenesis phase.

Total ARGs abundance was reduced by $33.7 \%$ for the Control, while GO-50 and GO-100 deteriorated the ARGs reduction, and the total ARGs abundance reduction was $3.7 \%$ and $23.9 \%$, respectively. GO-5 influenced the reduction little (32.8\%), but GO-500 enhanced the reduction to $40.2 \%$. The deterioration of ARGs abundance reduction could be attributed to the enhancement of HGT by GO, which could be reflected by the higher intI1 abundance at GO-50 and GO-100 (Fig. 4). Castrillón et al. (2015) reported that GO would make cells produce oxidative stress and the oxidative stress might change cell membrane fluidity, and then promote the conjugative transfer of resistance genes. It has been demonstrated that when $\mathrm{GO}$ concentration reached $50 \mathrm{mg}$ / L, the HGT frequency was the largest and increased by more than 10 times compared with the normal, but at higher GO concentrations ( $>50 \mathrm{mg} / \mathrm{L}$ ), the frequency gradually decreased (Guo and Zhang, 2017). Considering the complexity of swine manure AD system compared to the model experiment, the cutoff value may be $100 \mathrm{mg} / \mathrm{L}$. The enhancement of ARGs reduction at GO-500 could be explained by the absorbance and inhibitory proliferation of ARGs by GO, especially the extracellular ARGs (Yu et al., 2016; Zou et al., 2016). Thus, there existed a balance between the ARGs proliferation by the enhancement of HGT and ARGs destruction as for the ARGs changes caused by GO. However, GO addition had little influence on the MRGs reduction, but the intI1 reduction was deteriorated especially for GO-50.

\subsubsection{Changes of each ARG}

The abundance of some selected ARGs including tetM, tetX, bla $a_{\mathrm{CTX}-\mathrm{M}}$, ermF and sulII in the seed sludge was generally higher than swine manure, and the most abundant ARG was ermB $\left(1.56 \times 10^{-1}\right)$ and tetM $\left(1.32 \times 10^{-1}\right)$ for swine manure and the seed sludge, respectively. Except $p c o A$, other MRGs abundance including merA, ars $C$ and $c z c A$ in the seed sludge was also generally higher than swine manure. The abundance of VFs was comparable, while intI1 was higher in swine manure.

Although total ARGs abundance was reduced after AD, the fate of each ARG varied significantly (Table 2). Results showed that ermB, tetM, tet $G$, sulI, bla $a_{\mathrm{TEM}}$ and $m c r-1$ was reduced but tetX, sulII, ermF and $b l a_{\text {CTX-M }}$ were enriched after AD. The dominant ARGs like ermB and tet $M$ in swine manure could be effectively reduced by $63.85 \%$ and $36.88 \%$, respectively, but other ARGs should be paid more attention. Besides, AD could effectively reduce the $m c r-1$ gene abundance by 90.3-95.8\%. As for the MRGs, only merA was enriched, which indicated that the selection from $\mathrm{Hg}$ should be paid more attention. VFs including asa1 and eaeA were both largely reduced after AD.

Interestingly, the dynamics of each ARG varied significantly. For instance, sullI was enriched the most at the hydrolysis and acidogenesis, while tet $X$ was enriched the most at the acetogenesis and methanogenesis, and the reduction of $\operatorname{erm} B$ was realized at the acidogenesis with little changed as $\mathrm{AD}$ progressed. Although tet $G$ and $b l a_{\mathrm{TEM}}$ were enriched at acidogenesis, the reduction was realized at the methanogenesis phase, and tet $M$ changed little at acidogenesis while it was reduced after the acetogenesis phase. Also, it seemed like that the tendency of enrichment or reduction was determined at the hydrolysis and acidogenesis phase. There was no such variety for the changes of intI1, MRGs and VFs, and the reduction was realized at the hydrolysis and acidogenesis phase.

\subsection{Network analysis interpreting the discrepant dynamics of each ARG}

It was speculated that the discrepant dynamics of each ARG was attributed to their changes of host bacteria, and changes of microbial community contributed most to the changes of ARGs as previously supported (Forsberg et al., 2014; Su et al., 2015; Zhang et al., 2016b). Results of Mantel test and Procrustes analysis showed that there existed significant correlation between dynamics of ARGs and changes of microbial community $(\mathrm{R}=0.6956, \mathrm{p}=0.0001)$, and microbial community changes accounted for $63.8 \%$ of variance of ARGs profiles (Fig. S6).

Network analysis showing the potential host bacteria was conducted (Fig. 5), and the potential host bacteria of each ARG were listed (Table S6). The network analysis was divided into three modules: the first modules contained $b l a_{\text {СтX-M }}$, tet $X$ and their potential host bacteria, which was gradually enriched as $\mathrm{AD}$ progressed; the second module 

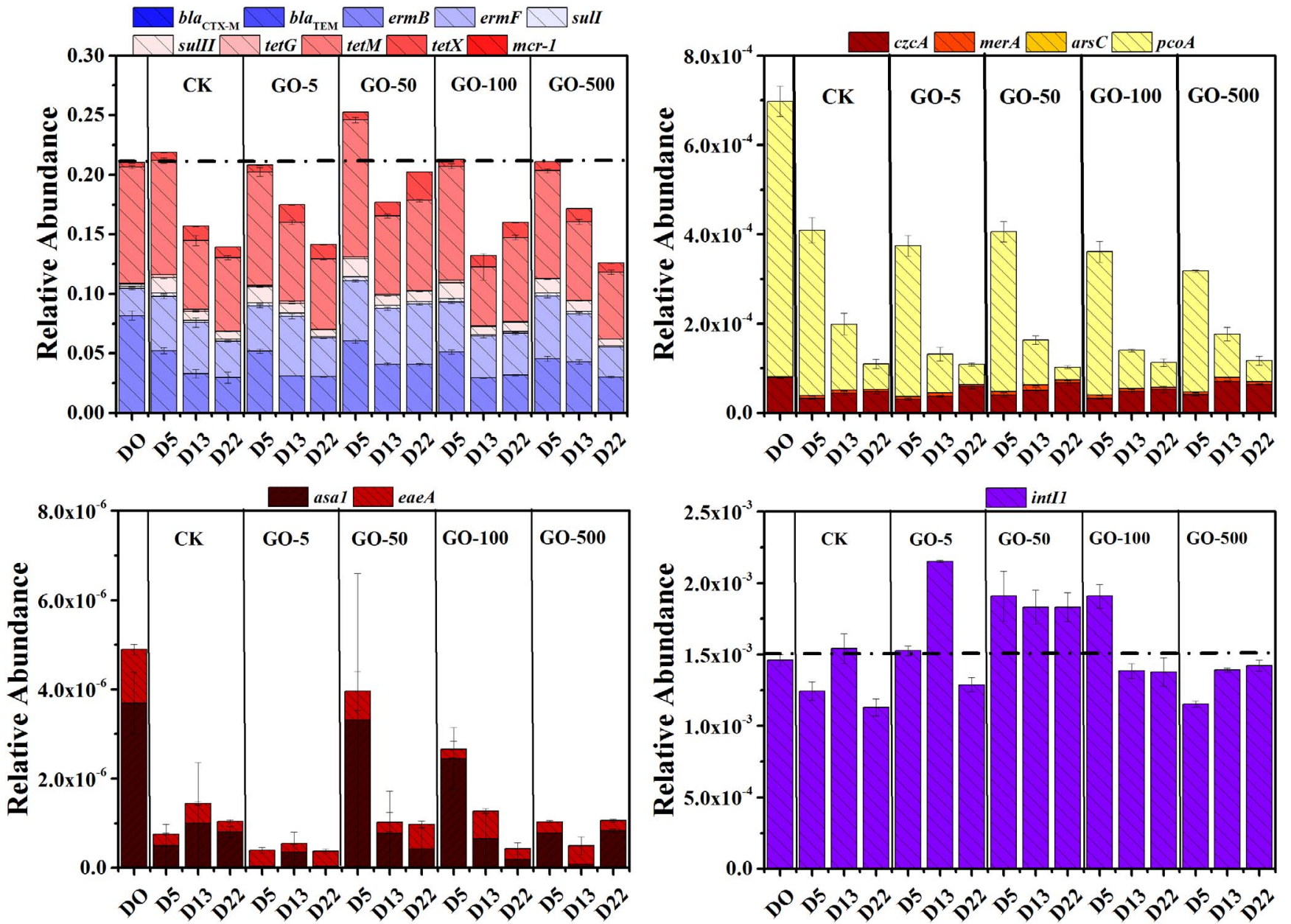

Fig. 4. The effects of GO addition on the changes of ARGs, MRGs, VFs and intI1.

Table 2

Evolution of ARGs, MRGs, VFs and intI1 along with swine manure AD compared to D0. ${ }^{\text {a }}$

\begin{tabular}{|c|c|c|c|c|c|c|c|c|c|c|c|c|c|c|c|c|c|c|}
\hline & iples & $b a_{c T: M}$ & $b a_{T E N}$ & ermB & ermF & sull & sullI & $\operatorname{tet} G$ & tetM & tet $X$ & $m c r-1$ & $c z c A$ & merA & & pcoA & asal & eеeA & intrl \\
\hline \multirow{6}{*}{ D5 } & Control & 1.50 & 2.47 & 0.64 & 1.99 & 1.63 & 6.38 & 5.07 & 0.98 & 1.73 & 0.29 & 0.41 & 5.00 & 0.11 & 0.60 & 0.13 & 0.22 & 0.85 \\
\hline & GO-5 & 1.08 & 2.36 & 0.63 & 1.67 & 1.40 & 683 & 1.55 & 0.98 & 1.46 & 0.42 & 0.39 & 4.64 & 0.30 & 0.55 & 0.01 & 0.29 & 1.05 \\
\hline & GO-50 & 1.74 & 2.62 & 0.74 & 2.22 & 1.79 & 7.72 & 2.22 & 1.18 & 1.66 & 0.33 & 0.51 & 6.04 & 0.40 & 0.58 & 0.90 & 0.54 & 1.31 \\
\hline & G0-100 & 0.92 & 2.33 & 0.63 & 1.84 & 1.57 & 6.66 & 3.64 & 0.98 & 1.47 & 0.31 & 0.41 & 5.80 & 0.17 & 0.52 & 0.66 & 0.18 & 1.31 \\
\hline & GO-500 & 1.46 & 1.35 & 0.56 & 2.32 & 1.43 & 5.68 & 1.29 & 0.93 & 2.00 & 0.18 & 0.52 & 4.09 & 0.65 & 0.44 & 0.21 & 0.21 & 0.79 \\
\hline & & 0.52 & 0.15 & 0.40 & 1.89 & 0.98 & 3.84 & 2.92 & 0.59 & 3.11 & 0.16 & 0.55 & 6.20 & 0.32 & 0.24 & 0.27 & 0.37 & 1.06 \\
\hline \multirow{4}{*}{ D13 } & D.5 & 1.31 & 1.51 & 0.38 & 2.19 & 1.58 & 3.98 & 3.21 & 0.68 & 3.76 & 0.12 & 0.47 & 6.15 & 0.32 & 0.14 & 0.10 & 0.15 & 1.47 \\
\hline & GO-5 & 1.72 & 2.09 & 0.50 & 2.06 & 1.51 & 4.04 & 2.24 & 0.67 & 2.99 & 0.12 & 0.63 & 9.69 & 0.96 & 0.16 & 0.21 & 0.21 & 1.26 \\
\hline & GO-100 & 1.45 & 0.63 & 0.36 & 1.54 & 0.78 & 3.32 & 1.24 & 0.51 & 2.48 & 0.11 & 0.61 & 4.50 & 0.53 & 0.14 & 0.18 & 0.52 & 0.95 \\
\hline & GO-500 & 1.61 & 1.3 & 0.53 & 1.76 & 1.20 & 4.41 & 0.61 & 0.67 & 2.89 & 0.27 & 0.89 & 6.55 & 1.28 & 0.16 & 0.02 & 0.35 & 0.95 \\
\hline \multirow{5}{*}{ D22 } & Control & 1.67 & 0.93 & 0.36 & 1.35 & 0.90 & 3.12 & 1.05 & 0.63 & 2.32 & 0.06 & 0.61 & 3.37 & 0.71 & 0.09 & 0.22 & 0.20 & 0.77 \\
\hline & GO-5 & 2.25 & 0.49 & 0.37 & 1.44 & 0.68 & 2.79 & 0.72 & 0.60 & 3.15 & 0.06 & 0.74 & 3.61 & 0.77 & 0.07 & 0.01 & 0.27 & 0.88 \\
\hline & GO-50 & 2.46 & 0.80 & 0.50 & 2.23 & 1.24 & 4.21 & 0.83 & 0.78 & 6.20 & 0.04 & 0.86 & 4.25 & 1.96 & 0.04 & 0.11 & 0.47 & 1.25 \\
\hline & GO-100 & 2.28 & 0.97 & 0.39 & 1.53 & 0.95 & 3.70 & 1.33 & 0.72 & 3.25 & 0.10 & 0.66 & 3.65 & 0.44 & 0.09 & 0.05 & 0.20 & 0.94 \\
\hline & $0-500$ & 2.04 & 1.06 & 0.37 & 1.11 & 0.59 & & 0.46 & 0.57 & 2.01 & 0.06 & 0.81 & 4.69 & 0.74 & 0.08 & 0.23 & 0.19 & 0.97 \\
\hline
\end{tabular}

\section{Minimum}

${ }^{\text {a }}$ Values were achieved by the temporary abundance divided by the abundance on D0. If the value $>1$, it meant that the gene was enriched. Or, it meant that the gene was reduced, and (1-minus the value) was the removal efficiency. The redder, the more it was reduced. The greener, the more it was enriched.

included ermB, tetM and $m c r-1$ which were reduced a lot after $\mathrm{AD}$, and the reduction was realized at the hydrolysis and acidogenesis phase; the third module contained those that was enriched at hydrolysis and acidogenesis phase and then the enrichment was reduced as AD progressed like $b l a_{\mathrm{TEM}}$, sulI, sulII and tetG. Some ARGs were even reduced to below the initial level like bla $a_{\mathrm{TEM}}$, sulI and tet $G$, while $e r m F$ was an exception whose enrichment changed little as $\mathrm{AD}$ progressed.

The potential host bacteria could well explain the discrepant changes of each gene during swine manure AD. For instance, the increasing enrichment of tetX and bla $a_{\mathrm{CTX}-\mathrm{M}}$ could be associated with Methanospirillum which also increased along with $\mathrm{AD}$, and Lactobacillus, Streptococcus and Atopostipes were all depicted to be the common host bacteria of ermB, tetM and $m c r-1$, and these bacteria mainly originated from swine manure and were reduced significantly after AD. These potential host bacteria may be not a real ARB yet, and the link was just functional, but it would make sense considering that the functional link make it have the best chance of becoming ARB (Zhang et al., 2016a). Besides, the identified host bacteria of mcr-1 (Escherichia) was also distinguished through network analysis, and Escherichia was also identified to be the host of ermB and tet $M$, while its abundance was reduced to below detection after $\mathrm{AD}$, which could also well explain the changes of ermB, tetM and $m c r-1$.

Not only the changes of its potential host influenced the ARGs dynamics, but also other factors like environmental variables (EVs), MRGs and $m c r A$ (the potential for biomethane production). Interestingly, the significant correlation between intI1 and any ARG considered was not observed, which indicated that $\mathrm{AD}$ could effectively reduce the role of HGT on ARGs. However, there existed significantly positive correlation between $m c r A$ and tetX and $b l a_{\mathrm{CTX} \text {-м }}$, while significantly negative correlation between $m c r A$ and other ARGs including ermB, tetM, $m c r-1$, tet $G$ and sull, which indicated that the increasing abundance of archaeal community for biogas production influenced ARGs abundance and the influence varied from ARG patterns. The most important MRGs concerning the ARGs profiles was $p c o A$, and it has significantly positive correlation with six ARGs, while the effects of EVs like TCOD, SCOD, proteins and polysaccharides on specific ARG dynamics could also not 

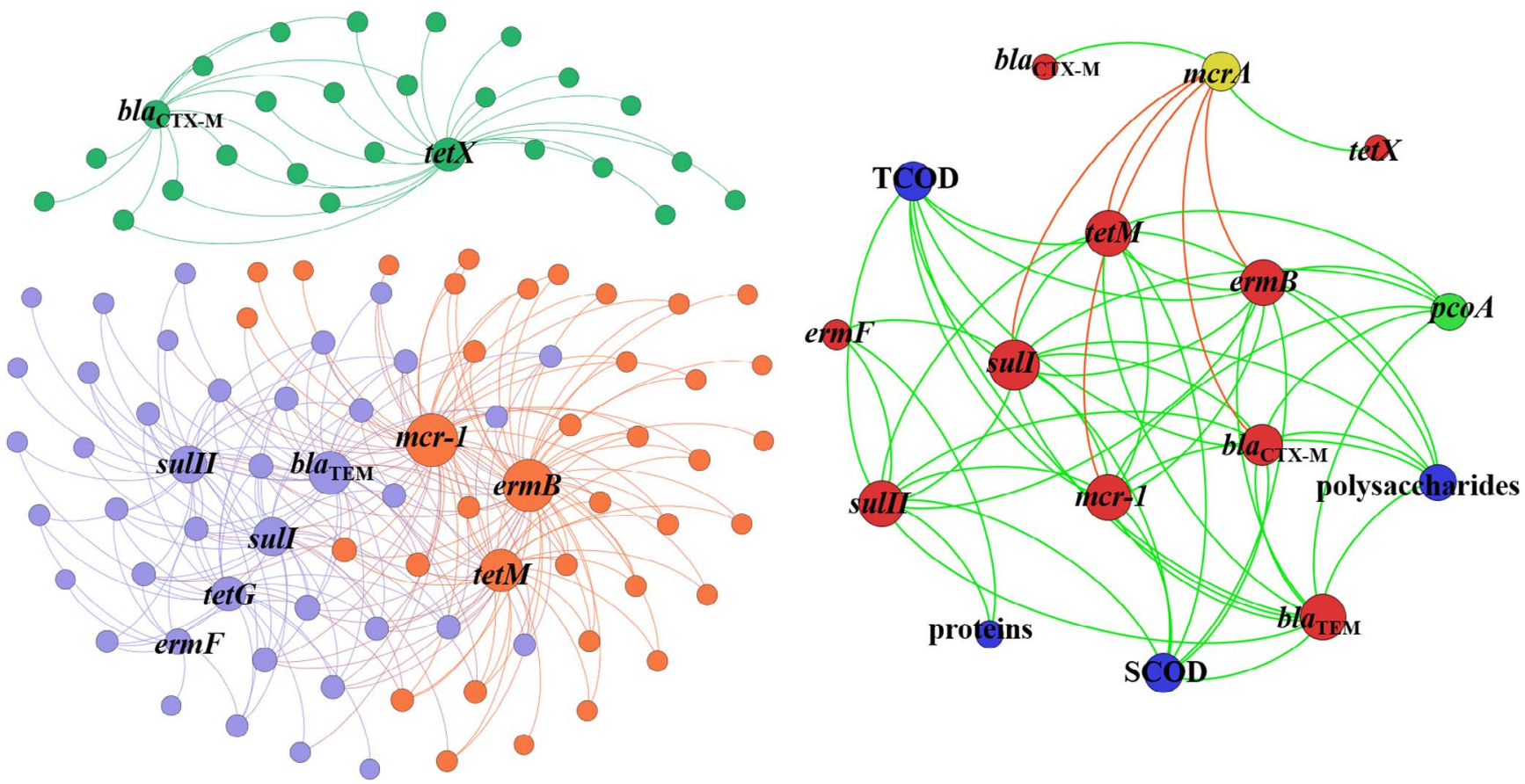

Fig. 5. Network analysis showing the potential host bacteria of each ARG (left) and the significant correlation between ARGs and other relevant genes (right).

be overlooked.

\subsection{SEM ranking the factors influencing the ARGs dynamics}

SEM could separate multiple pathways of influence and view them as a system, and is useful to explore the complex networks of relationships found in ecosystems (Hu et al., 2016). The a priori and theoretical assumptions were established before SEM, and the matrix values derived from the pairwise correlation between ARGs and the influencing factors were imported into the model for the construction of SEM. The overall goodness-of-fit of model fits was indicated by a nonsignificant chi-square test $(\mathrm{P}>0.05)$, high goodness-of-fit index (GFI $>0.90$ ), high adjust GFI (AGFI $>0.90$ ) and low root square mean errors of approximation (RMSEA < 0.05) (Hu et al., 2016).

SEM results shown in Fig. 6 indicated that the standardized effects

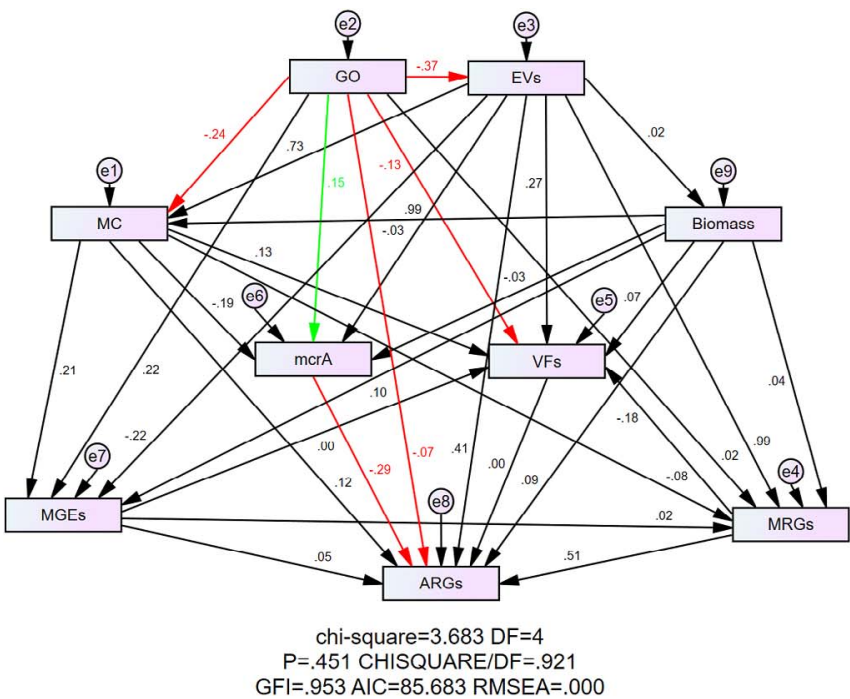

of GO and $m c r A$ on the ARGs was negative, that is, the increasing of GO and $m c r A$ abundance could avail the ARGs reduction, and GO indirectly affected the ARGs reduction while mcrA influenced the ARGs directly. While other factors like EVs, Biomass, microbial community (MC), MRGs and MGEs affected the ARGs positively, and EVs contributed the most to the ARGs in terms of standardized total effects followed by MRGs and MC, while the most direct effects come from the co-selection of heavy metals reflected by MRGs and the most indirect effects also come from EVs. GO could negatively influence the EVs, VFs and MC and then ARGs were negatively affected, while GO could directly and positively affected the MGEs $(\mathrm{R}=0.22)$, which was in accordance with the hypothesis that GO could boost the HGT of ARGs.

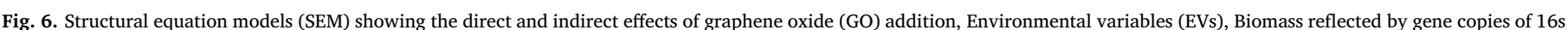

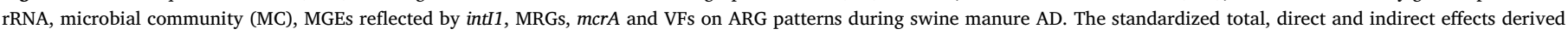
from the SEM results. 


\section{Conclusions}

Results in this study showed that the biological methane potential of swine manure was reduced due to GO addition. There existed limited influence on changes of bacterial and archaeal community composition by GO. AD could realize the reduction of ARGs abundance and higher concentration of GO could further enhance the reduction, while $50-100 \mathrm{mg} / \mathrm{L}$ of GO deteriorated ARGs reduction. Network analysis showed that microbial community variation could well explain the changes of each ARG, while SEM indicated that EVs contributed most to the changes of ARGs indirectly, GO influenced the ARGs changes negatively and MRGs influenced the most directly.

\section{Conflict of interest}

The authors declare no conflict of interest.

\section{Acknowledgement}

This work was supported by the National Major Science \& Technology Projects for Water Pollution Control and Management of China (2015ZX07203-007) and the State Key Joint Laboratory of Environmental Simulation and Pollution Control of China (16Z04ESPCR).

\section{Appendix A. Supplementary data}

Supplementary data associated with this article can be found, in the online version, at http://dx.doi.org/10.1016/j.biortech.2017.08.217.

\section{References}

Abdelsalam, E., Samer, M., Attia, Y.A., Abdel-hadi, M.A., Hassan, H.E., Badr, Y., 2017. Influence of zero valent iron nanoparticles and magnetic iron oxide nanoparticles on biogas and methane production from anaerobic digestion of manure. Energy 120, 842-853.

Ahmed, F., Rodrigues, D.F., 2013. Investigation of acute effects of graphene oxide on wastewater microbial community: a case study. J. Hazard. Mater. 256-257, 33-39.

Astals, S., Nolla-Ardèvol, V., Mata-Alvarez, J., 2012. Anaerobic co-digestion of pig manure and crude glycerol at mesophilic conditions: biogas and digestate. Bioresour. Technol. 110, 63-70.

Boeckel, T.P. Van, Brower, C., Gilbert, M., Grenfell, B.T., Levin, S.A., 2015. Global trends in antimicrobial use in food animals. PNAS 112, 5649-5654.

Chen, H., Gao, D., BingWang, Zhao, R., Guan, M., Zheng, L., Zhou, X., Chai, Z., Feng, W., 1 , 2014. Graphene oxide as an anaerobic membrane scaffold for the enhancement of B. adolescentis proliferation and antagonistic effects against pathogens E. coli and S. aureus. Nanotechnology 25, 165101.

Chen, S., Dong, X., 2005. Proteiniphilum acetatigenes gen. nov., sp. nov., from a UASB reactor treating brewery wastewater. Int. J. Syst. Evol. Microbiol. 55, 2257-2261.

Chen, S., Liu, X., Dong, X., 2005. Syntrophobacter sulfatireducens sp. nov., a novel syntrophic, propionate-oxidizing bacterium isolated from UASB reactors. Int. J. Syst. Evol. Microbiol. 55, 1319-1324.

Colunga, A., Rangel-mendez, J.R., Celis, L.B., Cervantes, F.J., 2015. Graphene oxide as electron shuttle for increased redox conversion of contaminants under methanogenic and sulfate-reducing conditions. Bioresour. Technol. 175, 309-314.

Dang, B., Mao, D., Xu, Y., Luo, Y., 2017. Conjugative multi-resistant plasmids in Haihe River and their impacts on the abundance and spatial distribution of antibiotic resistance genes. Water Res. 111, 81-91.

Engelstädter, J., Harms, K., Johnsen, P.J., 2016. The evolutionary dynamics of integrons in changing environments. ISME J. 10, 1296-1307.

Forsberg, K.J., Patel, S., Gibson, M.K., Lauber, C.L., Knight, R., Fierer, N., Dantas, G., 2014. Bacterial phylogeny structures soil resistomes across habitats. Nature 509, 612-616.

Fotidis, I.A., Karakashev, D., Angelidaki, I., 2014. The dominant acetate degradation pathway/methanogenic composition in full-scale anaerobic digesters operating under different ammonia levels. Int. J. Environ. Sci. Technol. 11, 2087-2094.

Garcia, J., 1990. Taxonomy and ecology of methanogens. FEMS Microbiol. Lett. 87, 297-308.

Garcia, J.L., Patel, B.K., Ollivier, B., 2000. Taxonomic, phylogenetic, and ecological diversity of methanogenic Archaea. Anaerobe 6, 205-226.

Guo, M.-T., Zhang, G.-S., 2017. Graphene oxide in the water environment could affect tetracycline-antibiotic resistance. Chemosphere 183, 197-203.

Hansen, K.H., Angelidaki, I., Ahring, B.K., 1998. Anaerobic digestion of swine manure: inhibition by ammonia. Water Res. 32, 5-12.

Hu, H., Wang, J., Li, J., Li, J., Ma, Y., Chen, D., 2016. Field-based evidence for copper contamination induced changes of antibiotic resistance in agricultural soils. Environ.
Microbiol. 18, 3896-3909.

Larson, C., 2015. China's lakes of pig manure spawn antibiotic resistance. Science 347, 704-705.

Lin, R., Cheng, J., Zhang, J., Zhou, J., Cen, K., Murphy, J.D., 2017. Boosting biomethane yield and production rate with graphene: the potential of direct interspecies electron transfer in anaerobic digestion. Bioresour. Technol. 239, 345-352.

Liu, Y.-Y., Wang, Y., Walsh, T.R., Yi, L.-X., Zhang, R., Spencer, J., Doi, Y., Tian, G., Dong, B., Huang, X., Yu, L.-F., Gu, D., Ren, H., Chen, X., Lv, L., He, D., Zhou, H., Liang, Z. Liu, J.-H., Shen, J., 2015. Emergence of plasmid-mediated colistin resistance mechanism MCR-1 in animals and human beings in China: a microbiological and molecular biological study. Lancet Infect. Dis. 3099, 1-8.

Luby, E., Ibekwe, A.M., Zilles, J., Pruden, A., 2016. Molecular methods for assessment of antibiotic resistance in agricultural ecosystems: prospects and challenges. J. Environ. Qual. 45, 441-453.

Narihiro, T., Terada, T., Ohashi, A., Kamagata, Y., Nakamura, K., Sekiguchi, Y., 2012. Quantitative detection of previously characterized syntrophic bacteria in anaerobic wastewater treatment systems by sequence-specific rRNA cleavage method. Water Res. 46, 2167-2175.

Pal, C., Bengtsson-palme, J., Kristiansson, E., Larsson, D.G.J., 2015. Co-occurrence of resistance genes to antibiotics, biocides and metals reveals novel insights into their co-selection potential. BMC Genomics 16, 964.

Palmieri, V., Lauriola, M.C., Ciasca, G., Conti, C., Spirito, M. De, Papi, M., 2017. The graphene oxide contradictory effects against human pathogens. Nanotechnology 28 152001.

Paton, A.A.W., Paton, J.C.J., 1998. Detection and characterization of shiga toxigenic Escherichia coli by using multiplex PCR assays for $s t x 1, s t x 2$, eaeA, enterohemorrhagic E. coli hlyA, rfbO111, and rfbO157. J. Clin. Microbiol. 36, 598-602.

Romero-Vargas Castrillón, S., Perreault, F., De Faria, A.F., Elimelech, M., 2015. Interaction of graphene oxide with bacterial cell membranes: Insights from force spectroscopy. Environ. Sci. Technol. Lett. 2, 112-117.

Schnürer, A., Nordberg, ̊., 2008. Ammonia, a selective agent for methane production by syntrophic acetate oxidation at mesophilic temperature. Water Sci. Technol. 57, 735-740.

Su, J.Q., Wei, B., Ou-Yang, W.Y., Huang, F.Y., Zhao, Y., Xu, H.J., Zhu, Y.-G.G., Ouyang, W., Wei, B., Huang, F.Y., Zhao, Y., Xu, H.J., Zhu, Y.-G.G., Ou-Yang, W.Y., Huang, F.Y., Zhao, Y., Xu, H.J., Zhu, Y.-G.G., 2015. Antibiotic resistome and its association with bacterial communities during sewage sludge composting. Environ. Sci. Technol. 49, 7356-7363.

Sui, Q., Zhang, J., Chen, M., Tong, J., Wang, R., Wei, Y., 2016. Distribution of antibiotic resistance genes (ARGs) in anaerobic digestion and land application of swine wastewater. Environ. Pollut. 213, 751-759.

Vankerckhoven, V., Autgaerden, T. Van, Vael, C., Lammens, C., Chapelle, S., Rossi, R. Jabes, D., Goossens, H., 2004. Development of a Multiplex PCR for the Detection of asa1, gelE, cylA, esp, and hyl Genes in Enterococci and Survey for Virulence Determinants among European Hospital Isolates of Enterococcus faecium. J. Clin. Microbiol. 42, 4473-4479.

Venkiteshwaran, K., Milferstedt, K., Hamelin, J., Fujimoto, M., Johnson, M., 2017 Correlating methane production to microbiota in anaerobic digesters fed synthetic wastewater. Water Res. 110, 161-169.

Wang, D., Wang, G., Zhang, G., Xu, X., Yang, F., 2013a. Using graphene oxide to enhance the activity of anammox bacteria for nitrogen removal. Bioresour. Technol. 131, 527-530.

Wang, G., Xu, X., Yang, F., Zhang, H., Wang, D., 2014. Using graphene oxide to reactivate the anaerobic ammonium oxidizers after long-term storage. J. Environ. Chem. Eng. 2, 974-980.

Wang, H., Dong, Y., Yang, Y., Toor, G.S., Zhang, X., 2013b. Changes in heavy metal contents in animal feeds and manures in an intensive animal production region of China. J. Environ. Sci. 25, 2435-2442.

Xie, Y., Wu, B., Zhang, X.X., Yin, J., Mao, L., Hu, M., 2016. Influences of graphene on microbial community and antibiotic resistance genes in mouse gut as determined by high-throughput sequencing. Chemosphere 144, 1306-1312.

Youngquist, C.P., Mitchell, S.M., Cogger, C.G., 2016. Fate of antibiotics and antibiotic resistance during digestion and composting: a review. J. Environ. Qual. 45, 537-545.

Yu, W., Zhan, S., Shen, Z., Zhou, Q., Yang, D., 2016. Efficient removal mechanism for antibiotic resistance genes from aquatic environments by graphene oxide nanosheet. Chem. Eng. J. 313, 836-846.

Zhang, B., Xia, Y., Wen, X., Wang, X., Yang, Y., Zhou, J., Zhang, Y., 2016a. The composition and spatial patterns of bacterial virulence factors and antibiotic resistance genes in 19 wastewater treatment plants. PLoS One 11, e0167422.

Zhang, C., Liu, X., Dong, X., 2004. Syntrophomonas curvata sp. nov., an anaerobe that degrades fatty acids in co-culture with methanogens. Int. J. Syst. Evol. Microbiol. 54, 969-973.

Zhang, J., Chen, M., Sui, Q., Tong, J., Jiang, C., Lu, X., Zhang, Y., Wei, Y., 2016b. Impacts of addition of natural zeolite or a nitrification inhibitor on antibiotic resistance genes during sludge composting. Water Res. 91, 339-349.

Zhang, J., Liu, J., Wang, Y., Yu, D., Sui, Q., Wang, R., Chen, M., Tong, J., Wei, Y., 2017. Profiles and drivers of antibiotic resistance genes distribution in one-stage and twostage sludge anaerobic digestion based on microwave- $\mathrm{H}_{2} \mathrm{O}_{2}$ pretreatment. Bioresour. Technol. 241, 573-581.

Zhang, J., Lv, C., Tong, J., Liu, J., Liu, J., Yu, D., Wang, Y., Chen, M., Wei, Y., 2016c. Optimization and microbial community analysis of anaerobic co-digestion of food waste and sewage sludge based on microwave pretreatment. Bioresour. Technol. 200, 253-261.

Zhang, J., Sui, Q., Tong, J., Buhe, C., Wang, R., Chen, M., Wei, Y., 2016d. Sludge biodrying: effective to reduce both antibiotic resistance genes and mobile genetic elements. Water Res. 106, 62-70. 
Zhang, Q.Q., Ying, G.G., Pan, C.G., Liu, Y.S., Zhao, J.L., 2015. Comprehensive evaluation of antibiotics emission and fate in the river basins of China: Source analysis, multimedia modeling, and linkage to bacterial resistance. Environ. Sci. Technol. 49, 6772-6782.

Zhilina, T.N., Appel, R., Probian, C., Brossa, E.L., Harder, J., Widdel, F., Zavarzin, G.A. 2004. Alkaliflexus imshenetskii gen. nov. sp. nov., a new alkaliphilic gliding carbohydrate-fermenting bacterium with propionate formation from a soda lake. Arch. Microbiol. 182, 244-253.
Ziganshin, A.M., 2014. Microbial community diversity in anaerobic reactors digesting turkey, chicken, and swine wastes. J. Microbiol. Biotechnol. 24, 1464-1472.

Ziganshin, A.M., Ziganshina, E.E., Kleinsteuber, S., Nikolausz, M., 2016. Comparative analysis of methanogenic communities in different laboratory-scale anaerobic digesters. Archaea 2016, Article ID 3401272.

Zou, W., Li, X., Lai, Z., Zhang, X., Hu, X., Zhou, Q., 2016. Graphene oxide inhibits antibiotic uptake and antibiotic resistance gene propagation. ACS Appl. Mater. Interfaces 8, 33165-33174. 